\title{
Bilateral inguinal hernia with uncommon content
}

Hayri Ogul MD, Ihsan Yuce MD, Suat Eren MD, Mecit Kantarci MD PhD

\section{CASE PRESENTATION}

A 56-year-old man was admitted to hospital with recurrent vomiting, left lower quadrant pain and bulges in both the left and right groin. The axial computed tomography (CT) scan (Figure 1) and threedimensional volume-rendering images (Figure 2) showed the antrum descended in the left inguinal canal together with a large amount of omental fat and small intestine, and herniation of the bladder toward the right inguinal canals.

\section{DISCUSSION}

Inguinal hernia is a common disorder that requires surgical management. Many organs can be associated with inguinal hernias, but the bladder, together with stomach involvement, is rarely encountered. To our knowledge, there is little information regarding stomach and bladder herniation in the same patient in the literature. First, only 60 cases of inguinal hernias involving the stomach have been described in the literature. Inguinal stomach herniation may be caused by gastric outlet obstruction and gastric rupture and, thus, early diagnosis is crucial (1). Second, bladder hernias are usually asymptomatic, but are often associated with intermittent swelling in the groin and significant lower urinary tract symptoms.

Most bladder hernias are direct, with a 70\% male predominance, and most cases occur on the right side. Inguinal bladder hernias are difficult to diagnose and fewer than $7 \%$ are diagnosed preoperatively. In addition, they can result in significant complications, such as bladder necrosis or acute renal failure (2). Accurate diagnosis is crucial to avoid bladder injury during surgery and other complications. Retrograde and voiding cystourethrogram (used only in suspected bladder herniation), ultrasonography, CT and magnetic resonance imaging are equally successful in establishing the diagnosis (2). However, CT is the most important diagnostic modality because it can identify the content of the hernia and rule out associated complications such as strangulation and hydronephrosis.

The differential diagnosis of inguinal hernia primarily includes the following potential conditions: femoral hernia, epididymitis, testicular torsion, inguinal adenopathy, groin abscess and lipoma. Finally, the standard treatment for inguinal hernia is surgical repair, and CT scan is the most useful diagnostic modality in its diagnosis.

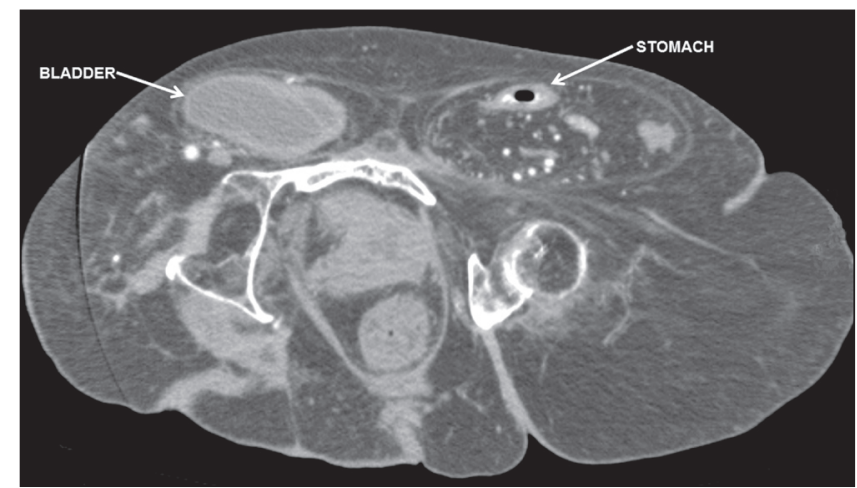

Figure 1) Axial computed tomography scan showing the antrum descended in the left inguinal canal and herniation of bladder toward the right inguinal canals
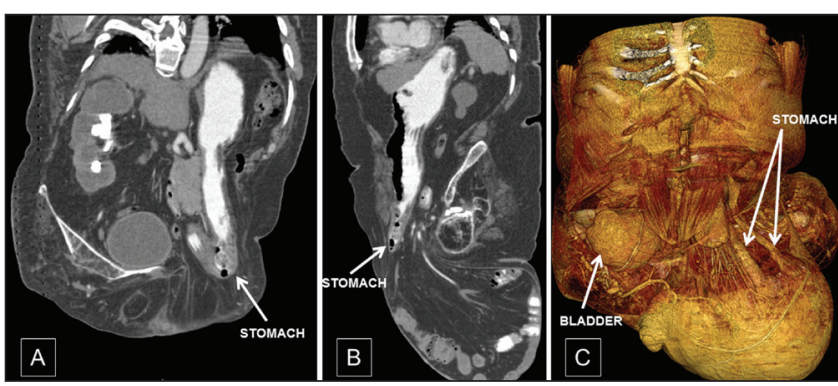

Figure 2) Sagittal (A) and coronal oblique (B) images showing the antrum descended in the left inguinal canal. A three-dimensional volume-rendering image $(\mathrm{C})$ shows the antrum descended in the left inguinal canal together with a large amount of omental fat and small intestine, and herniation of the bladder toward the right inguinal canals

\section{REFERENCES}

1. Kerschaever I, Poelmans S, Vankeirsbilck J, et al. Rare cause of gastric outlet obstruction: Incarcerated pylorus within an inguinal hernia. Ann R Coll Surg Engl 2012;94:e46-8.

2. Kim KH, Kim MU, Jeong WJ, et al. Incidentally detected inguinoscrotal bladder hernia. Korean J Urol 2011;52:71-3.

The Canadian Journal of Gastroenterology is now considering a limited number of submissions for IMAGE OF THE MONTH. These are based on endoscopic, histological, radiological and/or patient images, which must be anonymous with no identifying features visible. The patient must consent to publication and the consent must be submitted with the manuscript. All manuscripts should be practical and relevant to clinical practice, and not simply a case report of an esoteric condition. The text should be brief, structured as CASE PRESENTATION and DISCUSSION, and not more than 700 words in length. A maximum of three images can be submitted and the number of references should not exceed five. The submission may be edited by our editorial team.

Ataturk University, Erzurum, Turkey

Correspondence: Dr Hayri Ogul, Ataturk University, Erzurum 25240, Turkey. Telephone 90-442-2316751, e-mail drhogul@gmail.com

Received for publication September 16, 2012. Accepted September 20, 2012 


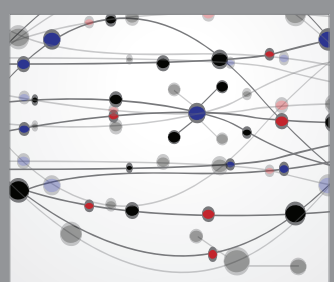

The Scientific World Journal
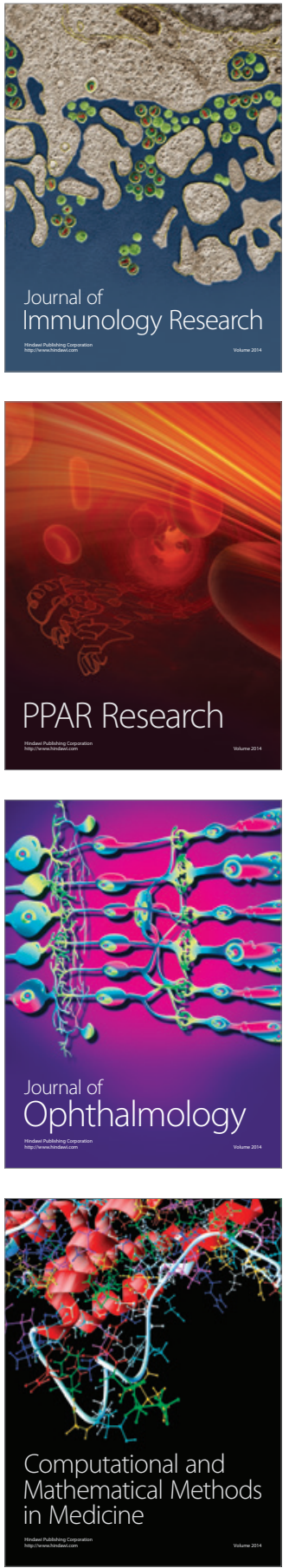

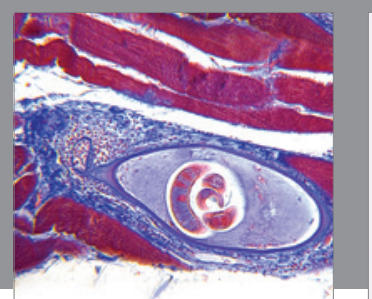

Gastroenterology Research and Practice

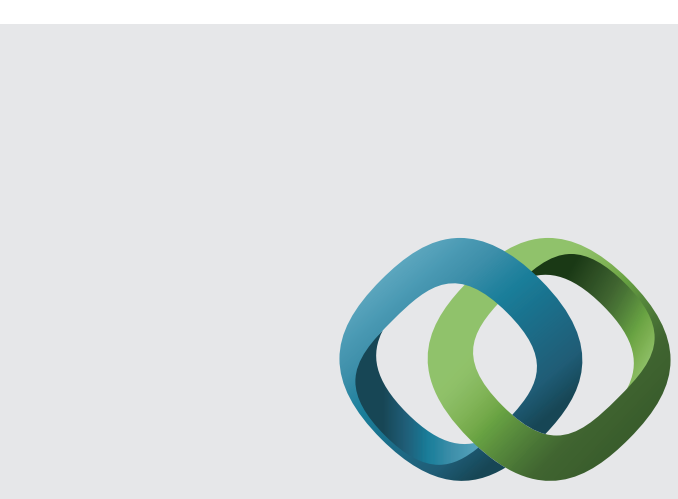

\section{Hindawi}

Submit your manuscripts at

http://www.hindawi.com
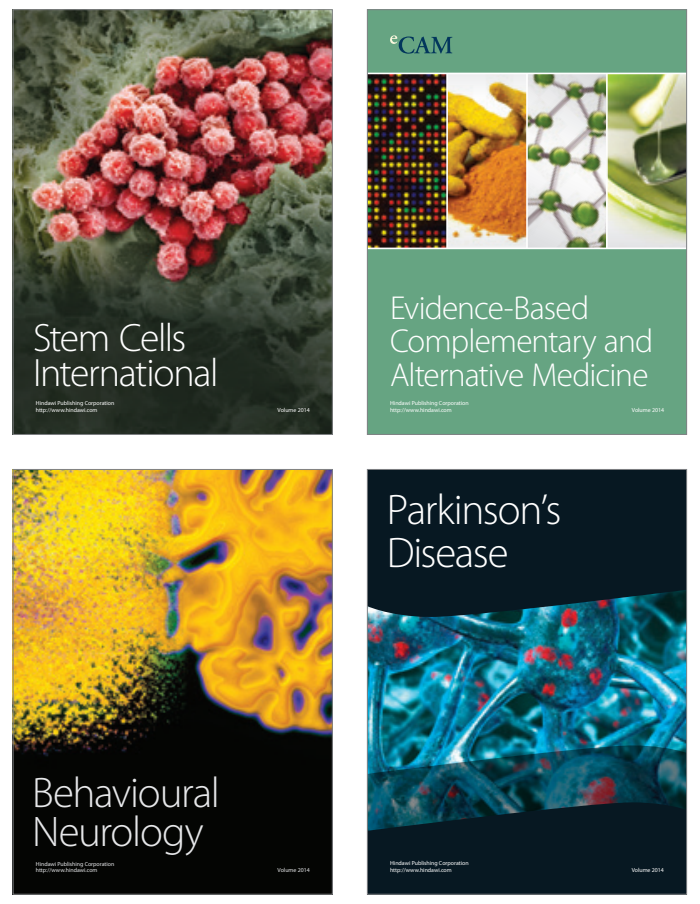
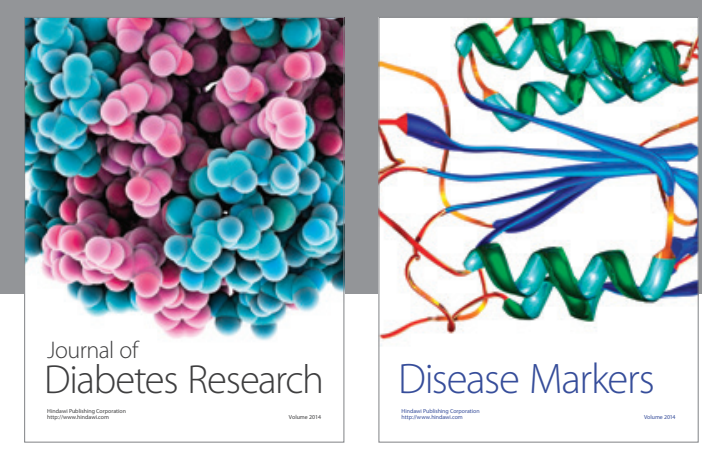

Disease Markers
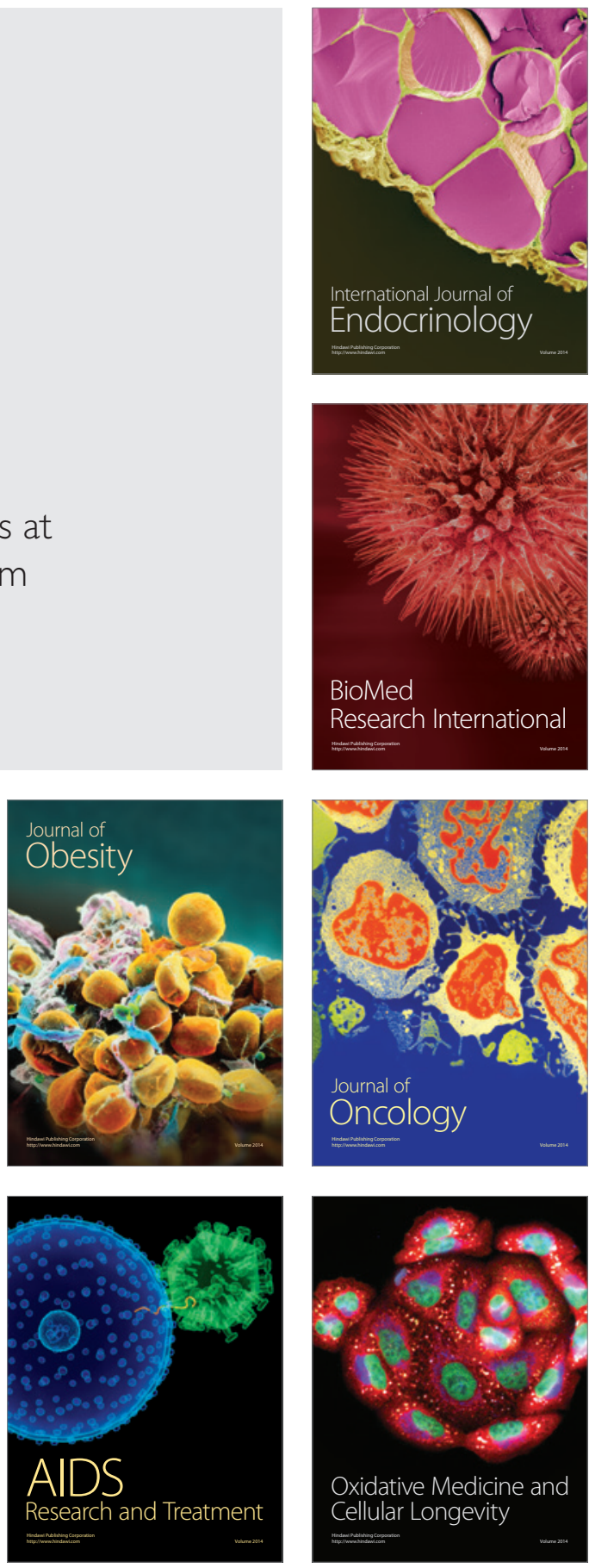